\title{
Relationship between left ventricular mass, wall thickness, and survival after subaortic septal myectomy for hypertrophic obstructive cardiomyopathy
}

\author{
Morgan L. Brown, MD, ${ }^{a}$ Hartzell V. Schaff, MD, ${ }^{\mathrm{b}}$ Joseph A. Dearani, MD, ${ }^{\mathrm{b}}$ Zhuo Li, MS, ${ }^{c}$ \\ Rick A. Nishimura, MD, ${ }^{\mathrm{d}}$ and Steve R. Ommen, $\mathrm{MD}^{\mathrm{d}}$
}

\begin{abstract}
Objective: In natural history studies, increased left ventricular mass and wall thickness are strongly associated with increased late mortality in patients with hypertrophic cardiomyopathy. Our objective was to determine the impact of left ventricular mass and wall thickness on survival after myectomy for hypertrophic obstructive cardiomyopathy.
\end{abstract}

\begin{abstract}
Methods: We reviewed the case histories of 796 patients who underwent transaortic septal myectomy for hypertrophic obstructive cardiomyopathy from January 1993 to December 2006. We then selected for study patients who had transthoracic echocardiography within 30 days after myectomy, which included complete measurements of interventricular wall thickness, posterior wall thickness, and left ventricular end diastolic dimension. Late survival was determined for all patients using medical records and surveys.
\end{abstract}

\begin{abstract}
Results: Our study group included 416 patients with a mean age of $50 \pm 15$ years, and 58\% were male. Eight percent of patients had coronary artery disease, $17 \%$ had a history of arrhythmia, and $17 \%$ had a previous or concomitant insertion of an internal cardioverter defibrillator. All patients had successful myectomy, and $17 \%$ required an additional mitral valve procedure, most often mitral valve repair. On predismissal echocardiography, the average interventricular wall thickness was $16 \pm 5 \mathrm{~mm}$, the posterior wall thickness was $13 \pm 3 \mathrm{~mm}$, and the left ventricular end diastolic dimension was $45 \pm 6 \mathrm{~mm}$. The indexed left ventricular mass was $135 \pm 46$ $\mathrm{g} / \mathrm{m}^{2}$. Late survival at 1,5 , and 10 years was $99 \%, 97 \%$, and $85 \%$, which was similar to that of an age- and gender-matched population $(P=.453)$. On multivariate analysis, preoperative and postoperative wall thickness and left ventricular mass were not associated with death; only a history of coronary artery disease (hazard ratio 4.9) was predictive of late mortality.
\end{abstract}

Conclusions: Left ventricular mass and wall thickness were not predictors of late survival after myectomy for hypertrophic obstructive cardiomyopathy, and this is in contrast to natural history studies of patients who were not treated surgically. Late survival was similar to that of an age- and gender-matched population. (J Thorac Cardiovasc Surg 2011;141:439-43)

Patients with hypertrophic cardiomyopathy (HCM) may have resting or provoked gradients owing to outflow tract obstruction caused by basal septal hypertrophy and systolic anterior motion of the mitral valve apparatus. In these patients, who are often symptomatic, transaortic septal myectomy can successfully relieve gradients. In multiple studies, ${ }^{1-3}$ septal myectomy for hypertrophic obstructive cardiomyopathy (HOCM) has been shown to have a low operative mortality $(<1 \%)$ and morbidity, and late

\footnotetext{
From the Department of Anesthesiology and Pain Medicine, ${ }^{a}$ University of Alberta, Edmonton, Alberta, Canada; Divisions of Cardiovascular Surgery, ${ }^{\text {b }}$ Biostatistics, ${ }^{c}$ and Cardiovascular Medicine, ${ }^{\mathrm{d}}$ Mayo Clinic, Rochester, Minn.

Disclosures: Authors have nothing to disclose with regard to commercial support.

Received for publication Aug 9, 2009; revisions received Dec 20, 2009; accepted for publication April 16, 2010; available ahead of print Sept 10, 2010.

Address for reprints: Hartzell Schaff, MD, Mayo Clinic, 200 First Ave SW, Rochester, MN 55905 (E-mail: schaff@mayo.edu).

$0022-5223 / \$ 36.00$

Copyright (C) 2011 by The American Association for Thoracic Surgery

doi:10.1016/j.jtcvs.2010.04.046
}

survival of patients after myectomy is similar to that of an age- and gender-matched population.

The mechanism whereby septal myectomy improves survival of patients with HOCM is poorly understood. In patients with obstructive or nonobstructive HCM who are not treated surgically, a correlation between left ventricular (LV) wall thickness and risk of sudden death, progression to heart failure, and overall death has been identified. ${ }^{4}$ Our objective was to determine the impact of LV wall thickness and LV mass on survival after septal myectomy for HOCM.

\section{METHODS}

After obtaining appropriate institutional review board approval waiving the need to obtain specific patient consent, we reviewed the case histories of 796 patients who underwent myectomy for HOCM from January 1993 to December 2006. Patients were selected for further study if complete early postoperative (<30 days) transthoracic echocardiography was available. Data were collected from both prospective clinical databases and a prospective echocardiographic database. Late survival was determined for all patients from medical records, Accurint (www.accurint.com), and surveys

Echocardiography was considered complete if it included comprehensive measurements of interventricular septal wall thickness (IWT), 


$$
\begin{aligned}
& \text { Abbreviations and Acronyms } \\
& \begin{aligned}
\text { HCM }=\text { hypertrophic cardiomyopathy } \\
\text { HOCM }=\text { hypertrophic obstructive } \\
\text { cardiomyopathy } \\
\text { ICD }=\text { internal cardioverter defibrillator } \\
\text { IWT }=\text { interventricular septal wall thickness } \\
\text { LV }=\text { left ventricle (ventricular) } \\
\text { MWT }=\text { maximal wall thickness } \\
\text { PWT }=\text { posterior wall thickness }
\end{aligned}
\end{aligned}
$$

posterior wall thickness (PWT), and LV end-diastolic dimensions. Maximal wall thickness (MWT) was considered to be the thickest wall of the LV (posterior or septal). Echocardiographic measurements were performed according to the standards described by the American Association for Echocardiography. ${ }^{5}$ We analyzed both the premyectomy and postmyectomy value for the IWT to account for any possible error resulting from a measurement in the myectomy trough. All measurements were also indexed to body surface area.

Statistical analyses were performed using SAS software (version 9.1; SAS Institute, Inc, Cary, NC). Data are presented as means and standard deviations or numbers and percentages, as appropriate. Univariate and stepwise multivariate models were created using logistic regression for binary outcomes and Cox proportional hazards for time-related data. KaplanMeier curves were compared using a log-rank test.

\section{RESULTS}

Our study group included 416 patients with a mean age of $50 \pm 15$ years, and $58 \%$ were male. Eight percent of patients had coronary artery disease, $17 \%$ had a history of arrhythmia, and $17 \%$ had a previous or concomitant insertion of an internal cardioverter defibrillator (ICD) (Table 1).

Before the operation, the mean echocardiographic measurement of IWT was $19.4 \pm 5.6 \mathrm{~mm}$, PWT was $14.0 \pm 3.3 \mathrm{~mm}$, and MWT was $19.5 \pm 5.6 \mathrm{~mm}$. The average $\mathrm{LV}$ end-diastolic dimension was $44.9 \pm 6.3 \mathrm{~mm}$ and $\mathrm{LV}$ mass index was $162.5 \pm 55.8 \mathrm{~g} / \mathrm{m}^{2}$. The mean ejection fraction was $72 \% \pm 6 \%$.

All patients had successful myectomy, and $17 \%$ required an additional mitral valve procedure including chordal or papillary muscle division or resection $(\mathrm{n}=34)$, mitral valve replacement $(n=9)$, leaflet only repair $(n=15)$, leaflet repair and annuloplasty $(n=7)$, or annuloplasty alone $(n=6)$. Forty-one patients required aortic valve procedures, with aortic valve replacement $(n=21)$ the most common for concomitant aortic stenosis. Coronary artery bypass was performed in 28 patients and a maze procedure in 11 patients.

On predismissal echocardiography, the average IWT was $15.9 \pm 4.9 \mathrm{~mm}$, the PWT was $13.1 \pm 2.9 \mathrm{~mm}$, and the $\mathrm{LV}$ end-diastolic dimension was $44.5 \pm 6.4 \mathrm{~mm}$. The average indexed LV mass was $134.7 \pm 45.9 \mathrm{~g} / \mathrm{m}^{2}$ and the MWT was $16.3 \pm 14.7 \mathrm{~mm}$ after subaortic septal myectomy. The ejection fraction was $66 \% \pm 7 \%$ at dismissal.
The mean follow-up time was $3.6 \pm 3.2$ years. Late survival at 1,5 , and 10 years was $99 \%, 97 \%$, and $85 \%$, which was similar to an age- and gender-matched Minnesotan population $(P=.453)$ (Figure 1). Univariate analysis is shown in Table 2. Significant univariate associations with mortality included older age, presence of coronary artery disease, and lower preoperative ejection fraction. Survival was similar for patients with and without ICDs. Wall thickness was not a univariate predictor of survival when considered as a continuous or integer variable (Figure 2). On multivariate analysis, wall thickness (preoperative and predismissal) and LV mass were not associated with death; only a history of coronary artery disease (hazard ratio 4.9; $P=.006$ ) was predictive of late mortality (Figure 3 ).

\section{DISCUSSION}

In this study of patients who underwent transaortic subaoertic septal myectomy for HOCM, measures of LV hypertrophy (IWT, PWT, MWT, LV mass, and indexed values) were not associated with late death. Our findings differ from the natural history of patients with HCM who were not treated surgically. In a study of 480 patients who were followed up over a mean interval of 6.5 years, Spirito and associates $^{4}$ found a strong correlation between degree of ventricular hypertrophy (defined as MWT) and sudden cardiac death. Indeed, in their investigation, the cumulative risk of sudden death 20 years after diagnosis was negligible for patients with a wall thickness of $19 \mathrm{~mm}$ or less but almost $40 \%$ for patients with wall thicknesses of $30 \mathrm{~mm}$ or more. Only $25 \%$ of the overall group had outflow tract obstruction, and only $5.4 \%$ had surgery for septal myectomy. ${ }^{4}$

The present study differs in several important ways. Our study patients appear to have less severe concentric ventricular hypertrophy than do those in the natural history study who had an average MWT of $21 \pm 5 \mathrm{~mm}$ including 43 patients $(9 \%)$ with an MWT of $30 \mathrm{~mm}$ or more. ${ }^{4}$ In our study, only $18(4 \%)$ patients had a preoperative MWT of $30 \mathrm{~mm}$ or more. It may be that patients selected for surgery who have marked basal hypertrophy have less severe thickening of the remainder of the ventricle.

As well, our study patients were more severely symptomatic, inasmuch as $81 \%$ were in New York Heart Association class III or IV compared with only $7 \%$ in the investigation by Spirito and associates. ${ }^{4}$ In a study from Italy of HOCM patients with severe symptoms, deteriorating functional class became a predictor of cardiovascular death, independent of outflow tract gradient. ${ }^{6}$ Spirito's group ${ }^{4}$ reported that extreme hypertrophy was associated with younger age but not associated with advanced symptoms. We did not include children in our study, whereas their study included some patients less than 18 years of age.

Finally, our analysis includes both unindexed and indexed values for LV hypertrophy. Although we acknowledge Spirito and colleagues' ${ }^{4}$ arguments for using the more 
TABLE 1. Patient demographics

\begin{tabular}{lc}
\hline \multicolumn{1}{c}{ Variable } & Mean \pm SD \\
\hline Age $(\mathrm{y})$ & $50 \pm 15$ \\
Body surface area $\left(\mathrm{m}^{2}\right)$ & $2.0 \pm 0.2$ \\
Ejection fraction $(\%)$ & $72 \pm 6$ \\
\hline & $\mathbf{N}(\%)$ \\
\hline Male & $242(58)$ \\
Coronary artery disease (MI or CABG) & $34(8)$ \\
Angina & $153(37)$ \\
New York Heart Association class III or IV & $337(81)$ \\
History of congestive heart failure & $40(10)$ \\
History of arrhythmia & $72(17)$ \\
Preoperative or concomitant ICD & $69(17)$ \\
\hline$M I$, Myocardial infarction; $C A B G$, coronary artery bypass grafting; $I C D$, internal \\
cardioverter defibrillator.
\end{tabular}

clinical relevant unindexed measures, we included indexed data to provide a more complete analysis. We did not find indexed values to be superior to the unindexed measures in our study.

In a study by Sorajja and colleagues, ${ }^{7}$ patients who had massive myocardial hypertrophy (myocardial thickness $\geq 30 \mathrm{~mm}$ ) had a poorer survival than did an age- and gender-matched population. The most common cause of death was sudden cardiac death in young $(<30$ years) patients and heart failure in older ( $\geq 60$ years) patients. These authors did not identify any excess mortality in middle-aged patients. Our study differs, in that this cohort includes patients with HOCM who had surgical relief of the LV outflow tract obstruction.

LV outflow tract obstruction appears to be a risk factor for poor outcome in patients with $\mathrm{HCM}^{8,9}$ The presence of a resting $\mathrm{LV}$ outflow tract gradient of $30 \mathrm{~mm} \mathrm{Hg}$ or more is reported to be an independent predictor (odds ratio 4.4) of progression to heart failure and death from heart failure or stroke in patients with $\mathrm{HCM}^{8}{ }^{8}$ However, in the study

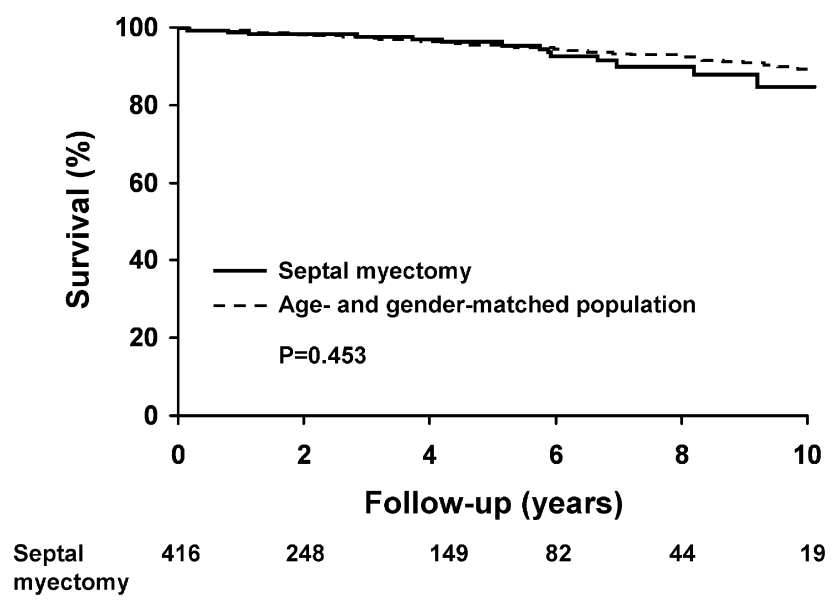

FIGURE 1. Overall survival after transaortic interventricular septal myectomy for hypertrophic obstructive cardiomyopathy compared with an age- and gender-matched Minnesotan, white population.
TABLE 2. Univariate predictors of mortality

\begin{tabular}{lc}
\hline \multicolumn{1}{c}{ Preoperative clinical variables } & $\boldsymbol{P}$ value \\
\hline Coronary artery disease & $\mathbf{. 0 0 6}$ \\
Older age (1 y) & $\mathbf{. 0 2 0}$ \\
New York Heart Association class III or IV & .136 \\
Male gender & .334 \\
Congestive heart failure & .554 \\
Preoperative/concomitant internal cardiac defibrillator & .845 \\
Angina & .872 \\
Preoperative arrhythmia & .905 \\
\hline \multicolumn{1}{c}{ Echocardiographic variables $\dagger$} \\
\hline Preoperative & $\mathbf{P \text { value }}$ \\
Decreasing ejection fraction (1\%) \\
Interventricular wall thickness & $\mathbf{. 0 4 4}$ \\
Indexed interventricular wall thickness & .843 \\
Postoperative & .392 \\
Interventricular wall thickness & .065 \\
Indexed interventricular wall thickness & .885 \\
Posterior wall thickness & .279 \\
Indexed posterior wall thickness & .070 \\
Left ventricular end-diastolic dimension & .057 \\
Indexed left ventricular end-diastolic dimension & .557 \\
Left ventricular mass & .402 \\
Indexed left ventricular mass & .681 \\
Maximal wall thickness & .733 \\
Indexed maximal wall thickness & .776 \\
\hline *Significant univariate associations with mortality. $\dagger$ All echocardiographic variables \\
were analyzed in a continuous fashion.
\end{tabular}

by Ommen and colleagues ${ }^{1}$ from our clinic, patients with obstruction who subsequently had interventricular septal myectomy had improved survival (hazard ratio 0.43 ) compared with patients not treated surgically, and this association was independent of other clinical or hemodynamic characteristics. The difference in survival of HOCM patients with or without septal myectomy may be related to relief of the hemodynamic burden and/or improvement in diastolic function. Improvement of mitral inflow Doppler velocity curves and decreased mitral E velocity suggest enhancement of diastolic filling after surgical myectomy. ${ }^{10}$ The improvement in diastolic function may be due to a decrease in subendocardial ischemia resulting from lower intracavitary pressure after myectomy.

Subaortic septal myectomy also results in LV mass regression after successful relief of the LV outflow tract obstruction. In prior studies from our clinic, LV mass regression has been shown to occur early postoperatively and persist up to 2 years after operation. ${ }^{10,11}$ At less than 2 years after myectomy, a statistically significant reduction in the IWT and PWT was demonstrated. ${ }^{11}$ We did not examine late echocardiography in our study patients and thus cannot assess the potential role of LV mass regression over time.

Improved survival after septal myectomy may be related to decreased risk of sudden cardiac death. McLeod and 


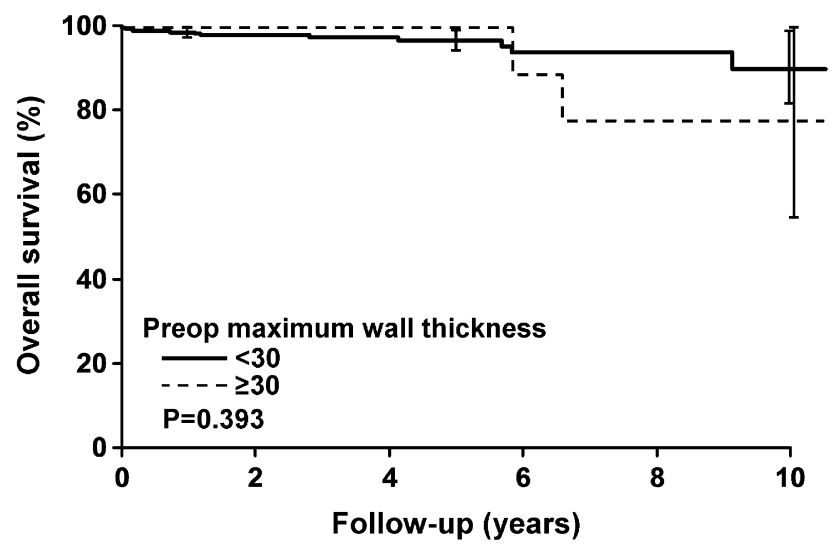

FIGURE 2. Survival stratified by preoperative maximal wall thickness. A maximal wall thickness of $30 \mathrm{~mm}$ or more was considered massive hypertrophy.

colleagues $^{12}$ reviewed 125 patients with HCM who had ICDs and stratified patients into groups who did or did not undergo myectomy. The average annualized event rate (sudden death or appropriate ICD discharge) was $4.3 \%$ per year in the nonmyectomy group and $0.24 \%$ per year after myectomy $(P=.004)$. The mechanism responsible for the lower risk of ventricular arrhythmias after myectomy is unknown, but the decrease in LV pressure may be a contributor. The late ( $>5$ years) frequency of sudden death after myectomy, however, remains uncertain, and ongoing assessment for the risk of sudden death is important.

It is notable that survival after subaortic septal myectomy in this series was similar for patients with and without ICDs, but these data should be interpreted with caution. Recent guidelines ${ }^{13}$ advise placement of a prophylactic ICD in patients with HCM who have a major risk factor for sudden death (prior cardiac arrest, spontaneous sustained ventricular tachycardia, family history of sudden cardiac death, syncope, an abnormal blood pressure response to exercise, and massive LV hypertrophy $\geq 30 \mathrm{~mm}$ ). However, our study contained only 18 premyectomy patients and 9 postmyectomy with an MWT of $30 \mathrm{~mm}$ or more. Thus, our results may not be applicable in patients with severe ventricular hypertrophy. Almost 17\% of our patients had an ICD either preoperatively or at the time of the operation, but we did not find that an ICD was protective in our patients.

In this cohort of patients, the only associations with late mortality were older age, coronary artery disease, and lower preoperative ejection fraction. On multivariate analysis, only coronary artery disease was predictive of late mortality. These risk factors would be similar to the common predictors of mortality in a generalized population. Coronary artery disease has previously been shown to impend a poor prognosis in patients with HCM, both surgically treated and not surgically treated. ${ }^{14}$

We used the clinically reported measurements on echocardiography for all patients. We did not remeasure

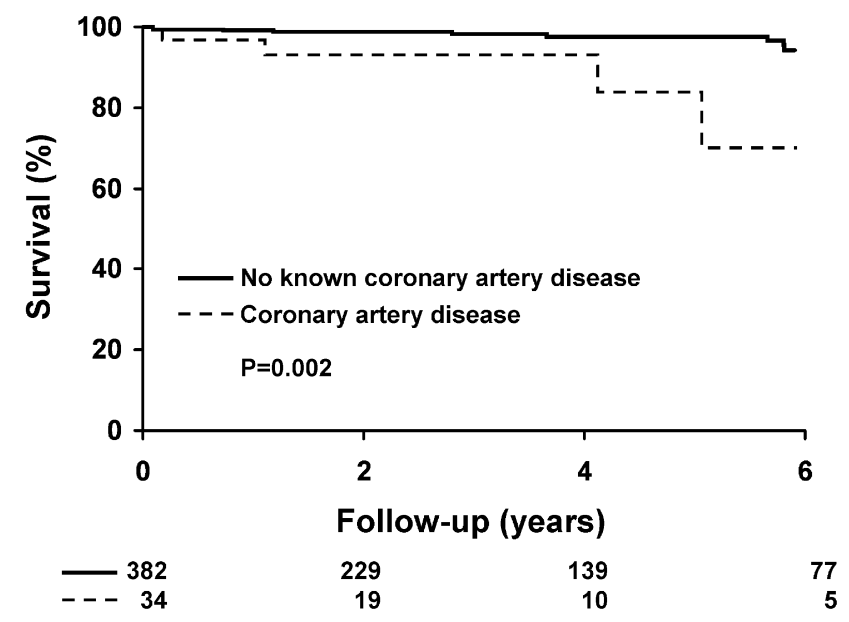

FIGURE 3. Survival stratified by presence or absence of coronary artery disease.

echocardiograms because this is the clinical information that was provided to make decisions regarding therapy. It is possible that the preoperative IWT and postoperative IWT measurements were taken in either the bulge of the interventricular septum or in myectomy trough. In an effort to account for this, both preoperative and postoperative measurements of IWT were included in our analysis. We also used both nonindexed and indexed values and calculated the MWT, which is a measurement reported in previous studies. ${ }^{1,4}$

\section{CONCLUSIONS}

The preoperative and postoperative LV mass and wall thickness, as well as the echo changes observed within 1 month of myectomy, were not predictors of late survival after myectomy for HOCM, and this is in contrast to natural history studies of patients who are not treated surgically. Late survival was similar to that of an age- and gendermatched population up to 10 years after myectomy. Longer-term follow-up is needed to determine both the mechanism of the improved survival and the duration of benefit.

\section{References}

1. Ommen SR, Maron BJ, Olivotto I, Maron MS, Cecchi F, Betocchi S, et al. Longterm effects of surgical septal myectomy on survival in patients with obstructive hypertrophic cardiomyopathy. J Am Coll Cardiol. 2005;46:470-6.

2. Smedira NG, Lytle BW, Lever HM, Rejeswaran J, Krishnaswamy G, Kaple RK, et al. Current effectiveness and risks of isolated septal myectomy for hypertrophic obstructive cardiomyopathy. Ann Thorac Surg. 2008;85:127-33.

3. Maron BJ. Controversies in cardiovascular medicine. Surgical myectomy remains the primary treatment option for severely symptomatic patients with obstructive hypertrophic cardiomyopathy. Circulation. 2007;116:196-206.

4. Spirito P, Bellone P, Harris KM, Bernabo P, Bruzzi P, Maron BJ. Magnitude of left ventricular hypertrophy and risk of sudden death in hypertrophic cardiomyopathy. N Engl J Med. 2000;342:1778-85.

5. Lang MB, Devereux RB, Flachskampf FA, Foster E, Pellikka PA, Picard MH, et al. Recommendations for chamber quantification: a report from the American Society of Echocardiography's Guidelines and Standards Committee and the 
Chamber Quantification Writing Group, developed in conjunction with the European Association of Echocardiography, a branch of the European Society of Cardiology. Available at: http://www.asefiles.org/ChamberQuantification.pdf

6. Autore C, Bernabo P, Stella Barilla C, Bruzzi P, Spirito P. The prognostic importance of left ventricular outflow obstruction in hypertrophic cardiomyopathy varies in relation to the severity of symptoms. J Am Coll Cardiol. 2005;45:1076-80.

7. Sorajja P, Nishimura RA, Ommen SR, Ackerman MJ, Tajik AJ, Gersh BJ. Use of echocardiography in patients with hypertrophic cardiomyopathy: clinical implications of massive hypertrophy. J Am Soc Echocardiogr. 2006;19:788-95.

8. Maron MS, Olivotto I, Betocchi S, Casey SA, Lesser JR, Losi MA, et al. Effect of left ventricular outflow tract obstruction on clinical outcome in hypertrophic cardiomyopathy. N Engl J Med. 2003;348:295-303.

9. Elliott PM, Gimeno JR, Tomé MT, Shah J, Ward D, Thaman R, et al. Left ventricular outflow tract obstruction and sudden death risk in patients with hypertrophic cardiomyopathy. Eur Heart J. 2006;27:1933-41.

10. Monteiro PF, Ommen SR, Bersh BJ, Dearani JA, Schaff HV, Nishimura RA, et al. Effects of surgical septal myectomy on left ventricular wall thickness and diastolic filling. Am J Cardiol. 2007;100:1776-8.
11. Deb SJ, Schaff HV, Dearani JA, Nishimura RA, Ommen SR. Septal myectomy results in regression of left ventricular hypertrophy in patients with hypertrophic obstructive cardiomyopathy. Ann Thorac Surg. 2004;78:2118-22.

12. McLeod CJ, Ommen SR, Ackerman MJ, Weivoda PL, Shen WK, Dearani JA, et al. Surgical septal myectomy decreases the risk for appropriate implantable cardioverter defibrillator discharge in obstructive hypertrophic cardiomyopathy. Eur Heart J. 2007;28:2583-8.

13. Epstein AE, DiMarco JP, Ellenbogen KA, Estes NA 3rd, Freedman RA Gettes LS, et al. ACC/AHA/HRS 2008 guidelines for device-based therapy of cardiac rhythm abnormalities: a report of the American College of Cardiology/ American Heart Association Task Force on Practice Guidelines (writing committee to revise the ACC/AHA/NASPE 2002 guideline update for implantation of cardiac pacemakers and antiarrhythmia devices): developed in collaboration with The American Association for Thoracic Surgery and Society of Thoracic Surgeons. Circulation. 2008;117:e350-408.

14. Sorajja P, Ommen SR, Nishimura RA, Gersh BJ, Berger PB, Tajik AJ. Adverse prognosis of patients with hypertrophic cardiomyopathy who have epicardial coronary artery disease. Circulation. 2003;108:2342-8. 